\title{
Experimental Investigation of Double Stage Air Intake in Throat-less Downdraft Biomass Gasifier
}

\author{
Hafif Dafiqurrohman ${ }^{I, 2^{*}}$, Adi Surjosatyo $^{I}$, and Muhammad Barryl Anggriawan ${ }^{l}$ \\ ${ }^{1}$ Department of Mechanical Engineering, Universitas Indonesia, Kampus UI Depok 16424, Indonesia \\ ${ }^{2}$ Indonesia Endowment Fund for Education (LPDP), Ali Wardhana Building, Ministry of Finance, Jakarta 10710, Indonesia
}

\begin{abstract}
Indonesia has a huge potential rice husk waste of $150 \mathrm{GJ} /$ year, a third more than the overall potential of biomass in Indonesia of $470 \mathrm{GJ} /$ year. Gasification of small-scale biomass fixed bed downdraft becomes one of the best solutions to become energy for power and heat generation. From studies that have been conducted abroad and from previous studies, the use of double stage air intake on the reactor proved effective in reducing tar because tar formed from the pyrolysis zone must pass through two zones below before then out with the gas producer. Implementation of secondary air intake at position $\mathrm{Z}=38 \mathrm{~cm}$ right on the pyrolysis zone, obtained results at ER 0.25 . With the same size, as much as $80.82 \%$ with tar content on the producer gas of 11.62 grams $/ \mathrm{Nm}^{3}$. While at ER 0.23 figures found the highest gasification efficiencvby $33.41 \%$.
\end{abstract}

\section{Introduction}

Indonesia has great biomass energy potential. From a recent study estimating the electrical potential of 150 million tons of biomass waste produced annually around $50 \mathrm{GW}$ or equivalent to $470 \mathrm{GJ} /$ year (Mujiyanto \& Tiess, 2013). The main source of biomass potential in Indonesia is agricultural waste, namely rice husks. In 2010, Indonesia produced $13,293,880$ tons of rice husk and increased to $14,166,400$ tons of rice husk in 2014 (FAO, 2015). This figure is equivalent to the energy potential of 150 GJ/year.

In Indonesia, small-scale gasifiers are the right choice to implement. In the form of an archipelagic state, energy needs for remote areas are the main focus. With the need for energy that is not too large, the use of gasifiers can accommodate electrification in remote areas so as to ensure the sustainability of energy at a low cost. In addition, compared to small-scale power plants, gasification is seen as more promising in terms of efficiency and ease of maintenance.

Fixed bed downdraft gasifier is a co-current reactor in which air enters the reactor through a certain position under the reactor roof. In this type, solid biomass fuel is introduced from the top of the gasifier and subjected to drying, pyrolysis, oxidation and reduction as the fuel moves to the bottom of the gasifier as shown in the figure below. Then, the resulting syngas comes out through the gas outlet located at the bottom of the reactor so that it is called downdraft.

Air is supplied with water nozzle on the side of the reactor and met with char particles from the pyrolysis zone to form a combustion zone (oxidation) with a temperature of about $1200-1400{ }^{\circ} \mathrm{C}$ as shown below. Then the formed gas moves again down through the hot char particles (gasification/reduction zone), resulting in gasification. The resulting ash leaves the gas and falls down the reactor.

Tar is a brownish black liquid particles carried along with syngas. The European standardization body defines tar as: "All the organic compounds present in syngas except hydrocarbon gases from $\mathrm{C} 1$ to $\mathrm{C} 6$ " (van de Kamp, de Wild, Knoef, Neeft, \& Kiel, 2006). The presence of tar in the gas producer can reduce the quality of the gas because tar is a non-combustible particle.

To improve the performance of the downdraft gasifier, the basic design of the gasifier can be modified. In this study, we focused on adding air supply to gasification reactors to achieve certain optimal operating parameters. The use of one level and atmospheric air supply is enhanced by the use of two levels of air supply system.

A multilevel air supply system has been developed to improve the performance of a 1-level air system. (Galindo et al., 2014) conducted a study on downdraft gasifiers with a 2-level air supply. The primary air is given at first level at $300 \mathrm{~mm}$ above the grate and secondary air is given at the second level at $400 \mathrm{~mm}$ above the primary air. The same gasifier is also used for Eucalyptus wood waste gasification by (Martínez, Silva Lora, Andrade, \& Jaén, 2011).

The application of 2-level air supply to Eucalyptus wood gasification increases the temperature of the 
pyrolysis process just like the oxidation temperature, resulting in a reduction of the tar content in the gas producer (Galindo et al., 2014). As the temperature of the pyrolysis zone increases, the lighter compounds are formed during the devolatilization of raw materials in the pyrolysis zone. So the compound is easier to break apart when it enters the combustion zone (Martínez et al., 2011).

In a study conducted by (Striugas, Zakarauskas, Džiugys, Navakas, \&Paulauskas, 2014), a 2-level air (primary and secondary) was fired into an oxidation zone through a circular nozzle and a tertiary level was fired into the reduction zone through a nozzle on a pipe along the vertical axis of the gasifier. The tertiary air keeps the temperature in a high and uniform reduction zone useful for tar breaking.

Another study by (Pan et al., 1999), by adding secondary air just above the point of feeding biomass on a fluidized bed with a temperature of $840-880{ }^{\circ} \mathrm{C}$, a tar reduction of 88.7 wt. $\%$.

(Narvaez et al., 1996) carried out the addition of a secondary air pad to a fluidized bed gasifier and observed an increase in temperature of about $70^{\circ} \mathrm{C}$ which resulted in a reduction of tar from 28 to 16 $\mathrm{g} / \mathrm{Nm}^{3}$.

Research conducted by (Ma et al., 2012) shows that with the addition of secondary air supply, it can increase the temperature up to $900^{\circ} \mathrm{C}$ in the oxidation zone and an increase in the heating value of syngas.

In this study, downdraft gasifier type was chosen because it has a low level of tar content compared to othergasifier design (Basu, 2010). In addition, downdraft gasifiers are suitable for small scale applications (Susastriawan, Saptoadi, \&Purnomo, 2017). University of Indonesia biomass gasification research team has conducted various research using downdraft fixed bed gasifier. The first one is experiment with circular air intake modification as a multi-stage air intake application with gasification efficiency (cold efficiency) is $30.2 \%$ for optimum gasification process and optimum operating temperature of pyrolysis zone is reached at $500-600{ }^{\circ} \mathrm{C}$ (Dafiqurrohman, 2015). The another is experiment with secondary air intake position variation showed optimum $Z$ result at position $38 \mathrm{~cm}$ from the top of the reactor and the opening of primary air intake $45^{\circ}$ with yield of lowest tar and highest energy (Gibran, 2016). And the last is addition to producing gas/syngas producer, gasification process also produces another residue one of them is tar. It is undeniable that tar is one of the greatest challenges due to its physical and chemical characteristics (having high molecular value and viscosity) which makes the gas unfit for use in direct use on thermal engines. So that, in gasification research, the tar reduction method became one of the important topics (Galindo et al., 2014).

Secondary air intake is shown to reduce tar significantly by increasing the temperature maintained at the gasification area. By adding secondary water just above the feeding point of biomass to fluidized bed with temperature $840-880{ }^{\circ} \mathrm{C}$, reduction of tar by 88.7 wt.\% (Pan, Roca, Velo, \&Puigjaner, 1999). Narv et al. did the addition of a secondary air pad to a fluidized bed gasifier and observed a temperature rise of about $70{ }^{\circ} \mathrm{C}$ which resulted in a reduction of tar from 28 to $16 \mathrm{~g} / \mathrm{Nm}^{3}$ (Narvaez, Orı, Aznar, \& Corella, 1996).

\section{Material and Method}

\subsection{Fuel ignition process}

The testing process (see Fig.1.) begins by adding rice husks as much as $0.78 \mathrm{~kg}$ as initial fuel. This amount has been set to position the fuel over the primary air supply to make the coal in the reactor. Furthermore, as much as about 5 drops of oil catalyst are added as the combustion catalyst evenly. When finished, rice husk is burned using a lighter. In this process, the primary air blower is lit for faster burning. This process takes about 5-10 minutes. Once the embers are formed, the top is then covered with a reactor to reduce the contact of the outside air entering the reactor.

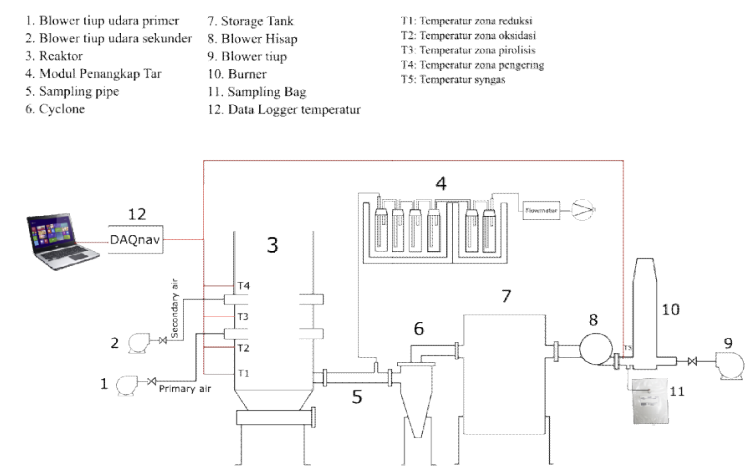

Fig. 1. Experimental Schematic

\subsection{The process of regulating the air flow into the reactor}

This process takes place separately. The primary air supply is lit at the beginning to assist the process of making the coal in the reactor. The air in the primary blower is set at a $45^{\circ}$ opening (ER 0.16) without variation.

While for secondary air supply, given when the process of gasification has taken place. This is because the secondary air position is in the pyrolysis zone so that the solid fuel must meet the zone. The air variations used are $30^{\circ}, 33^{\circ}, 35^{\circ}$, and $38^{\circ}$ according to the predicted Equivalence Ratio (ER) variation of 0.22 ; $0.23 ; 0.24$; and 0.25 . The ER scores were based on the last 2 years of research where the optimal ER values for gasifiers with rice husk fuels were 0.23 (Gibran, F.R., 2016) and 0.24 (Dafiqurrohman, 2015). Referring to 2 ER numbers obtained, in this study the authors widened the range of ER value variations from 0.22 to 0.25 with pause 0.01 .

\subsection{Gas producer withdrawal process with blower}

After the syngas is formed and lifted onto the reactor, the suction blower is turned on by turning the start button on the inverter and raising the frequency for the 
blower to rotate. In this test, the blower frequency applied is $18 \mathrm{~Hz}$. Blowers are used to pull syngas into the burner and prevent explosions in the reactor because syngas is a combustible gas.

\subsection{Syngas ignition process in gas producer}

After the syngas out of the burner, the ignition/ignition gas producer using the lighter. In this process of ignition, the air blower is turned on to create the right water fuel ratio so that faster combustion takes place.

\subsection{The process of adding rice husk to the reactor}

During the gasification process, the addition of solid fuel husk rice continues to be done for the process takes place. Each 98.77 grams of fuel is added while the coals are formed. This process is done until the syngas in the burner can't be burned. This is because the gasification system used is a batch system so that the ash at the bottom can't be directly out and replaced with new fuel so that one day the gasification process can be stopped.

\subsection{The process of taking the gas into the tar catching module}

This step is done after the fire burner burns in stable condition, about 1 minute after turn on. The process of draining the gas to the sampling pipe is done by opening the valve on the sampling pipe and switching on the vacuum pump for syngas to attract the tar catch module. After the vacuum pump is turned on, the pull is conditioned at 10 litres/minute by adjusting the valve in the rotameter. The tar sampling process is done for 8 minutes.

\subsection{Acetone evaporation process}

After the sampling process is complete, the fluid located on the 5 impinger tubes is mixed into 2 equal parts for ease in evaporation. 2 impinger tubes are then heated in a vessel containing water that is kept at 70 ${ }^{\circ} \mathrm{C}$. The evaporation process is carried out for 2 hours based on the calculation of tar evaporation rate that has been done.

\subsection{Gas-taking process to sampling bag}

The gas-taking process for the gas composition is tested after the temperature at the burner reaches a temperature of $800{ }^{\circ} \mathrm{C}$. Sampling bag is connected with gas sampling line that has been made by using silicon hoses. The gas-taking process is carried out until the sampling bag is fully loaded. Sampling bag that has been filled with syngas, then stored and taken to BPPT for testing the composition of the gas.

\section{Result and Discussion}

\subsection{Analysis of double air supply usage in reactors}

Secondary air intake is placed at $\mathrm{Z}=38 \mathrm{~cm}$ where in that position, the secondary air nozzle is precisely located in the pyrolysis zone. The addition of secondary air intake in this position aims to keep the temperature in the pyrolysis zone increased (Devi et al., 2003) and stable so that the process of breaking solid raw materials into other compounds proceeds well through the addition of air supply. As the air supply increases in the pyrolysis region, the heat energy received from the oxidation zone will increase as well. It is characterized by a rise in temperature in the pyrolysis zone.

With the addition of secondary air intake, as seen in Fig. 2. it was found that the temperature in the pyrolysis zone increased compared with no secondary air intake (ER 0.16) as shown in the graph below.

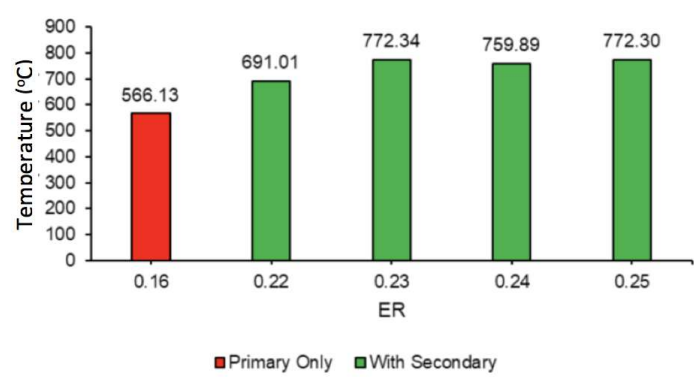

Fig. 2. Temperature of Pyrolysis Zone at every ER value

With the addition of secondary air intake, this resulted in a rise in temperature in the pyrolysis area so that tar breaking took place well as seen in Fig. 3. and obtained a decrease in tar content in the gas producer and produced a reduction efficiency of tar reached $80.82 \%$.

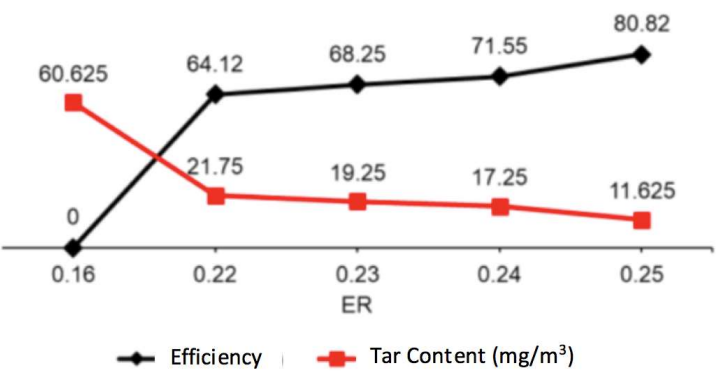

Fig. 3. Reduction of tar as ER increases

In addition to the temperature rise in the pyrolysis zone (see Fig. 4.), the addition of secondary air intake also increases the temperature in the oxidation zone. This is because the secondary air intake position is located in the lower pyrolysis zone so that the remaining oxygen from the secondary air moves down to the oxidation zone thus increasing the temperature of the oxidation zone. 


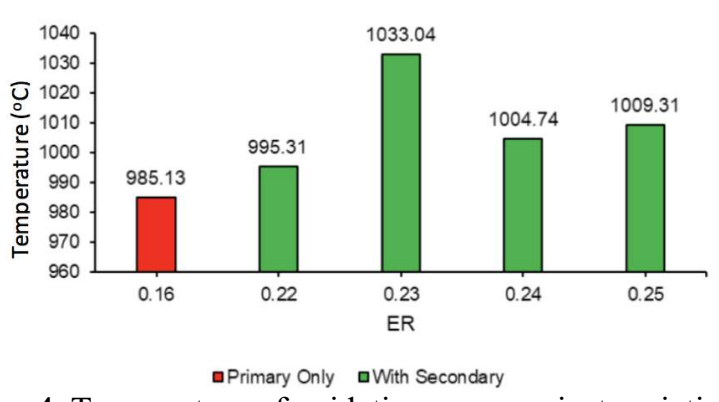

Fig. 4. Temperature of oxidation zone against variation of ER

With increasing oxidation and pyrolysis temperatures, the process of breaking solid raw materials in the pyrolysis zone forms a lighter tar compound so that upon entering the oxidation zone, the tar is easier to break apart so that the tar content in the gas producer decreases (Martínez et al., 2011).

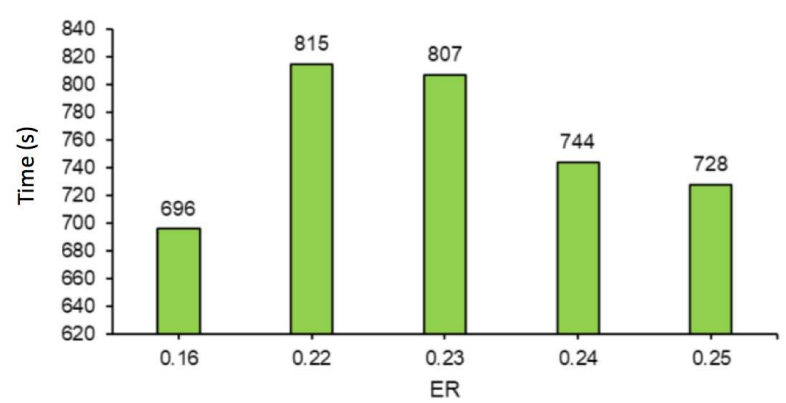

Fig. 5. Duration of gasification operation

The use of secondary air intake also increases the operating time of the gasifier. This is because with the secondary air intake then the operating temperature on the entire zone in the gasifier increases (see Fig. 5.). With higher operating temperatures, the gasification process in each zone takes place well because the energy required for each zone is not wasted to increase the temperature, but is used to maximize the process in each zone. If the reactions that occur in each zone take place well then the whole process of gasification will be good so that the duration of surgery increases. Increased duration of gasifier operation also affects the reduction of tar because the tar breaking process lasts longer so that more tar compounds are split.

\subsection{Analysis of The Lowest Tar Content}

(Galindo et al., 2014) suggested that the addition of secondary air intake to the reactor would increase the temperature of the pyrolysis zone and oxidation. As a result, the content of tar and impurity particles on the gas producer is reduced.

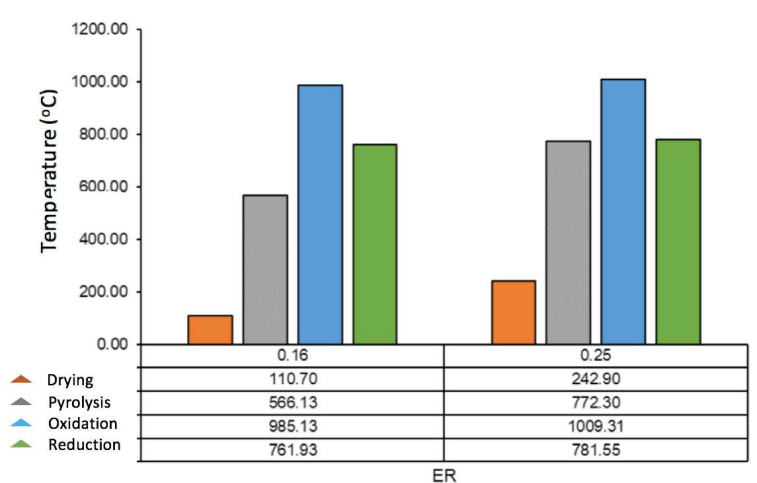

Fig. 6. Gasification operating temperature during ER 0.16 and 0.25

In the temperature graph above (Fig. 6.), the temperature at ER 0.25 has increased in each gasification zone compared to ER 0.16 (primary air only). At ER 0.25 ; the secondary air supply supplied to the reactor is $0.00042 \mathrm{~m}^{3} / \mathrm{s}$. This considerable amount of air affects the conditions inside the gasification reactor. With the air supply in the pyrolysis zone, the flaming phenomenon of pyrolysis occurs and thermal tar cracking takes place.

As ER increases, the air supply to the reactor increases. This results in a more complete combustion process in the pyrolysis zone resulting in more volatile reacting (volatile) air (oxygen) resulting in tar reduction (Kinoshita, Wang, \& Zhou, 1994).

This is consistent with the experiment carried out ie the temperature of each zone increased from $110.70{ }^{\circ} \mathrm{C}$ to $242.90{ }^{\circ} \mathrm{C}$ in the drying zone, $566.13{ }^{\circ} \mathrm{C}$ to 772.30 ${ }^{\circ} \mathrm{C}$ in the pyrolysis zone, $985.13{ }^{\circ} \mathrm{C}$ to $1009.31{ }^{\circ} \mathrm{C}$ in the oxidation zone, and $761.93{ }^{\circ} \mathrm{C}$ to $781.55{ }^{\circ} \mathrm{C}$ in the reduction zone.

Judging from the design of the reactor used is fixed bed downdraft, tar formed from the pyrolysis zone must pass through two zones below before then out with the gas producer. Two zones are oxidation and reduction where the temperature of the two zones is increased in this ER compared to ER 0.16. Practically at these temperatures, tar undergoes several times thermal tar cracking so that the amount of tar on the gas producer experiences the most significant decrease in this ER.

In addition to this ER drying zone temperature is also high, that is equal to $242.90{ }^{\circ} \mathrm{C}$. This results in the drying process and pre-heating going well so that later when solid fuel (rice husk) passes below the zone below, the energy available in the zone is focused for gasification reaction in each zone.

\subsection{Analysis of Highest Gasification Efficiency}

In addition to knowing the value of the lowest tar content, this study also aims to find the variation of ER with the highest value of gasification efficiency. From the calculation on point 4.6. obtained the highest gasification efficiency of $33.41 \%$ at ER 0.23 as seen in Fig. 7. These results can be analyzed based on some data that has been taken, ie temperature, operating duration, and gas composition. 


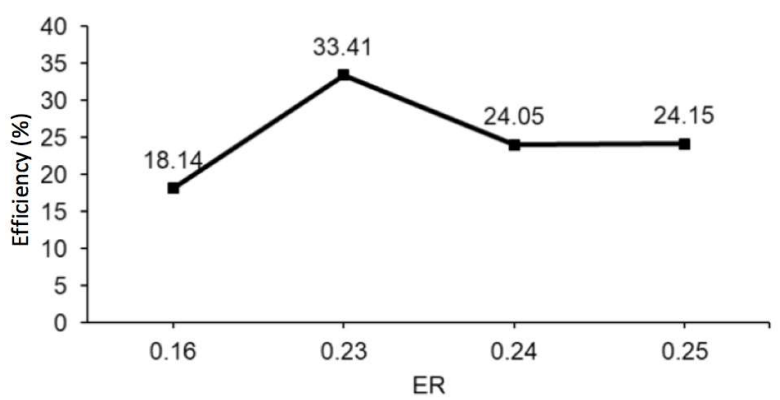

Fig. 7. Graph of Gasification Efficiency on ER.

Gasification efficiency is the ratio of the gas producer heating value content resulting from the biomass gasification process and the potential heat content of biomass when it is completely burned (coldgas efficiency).

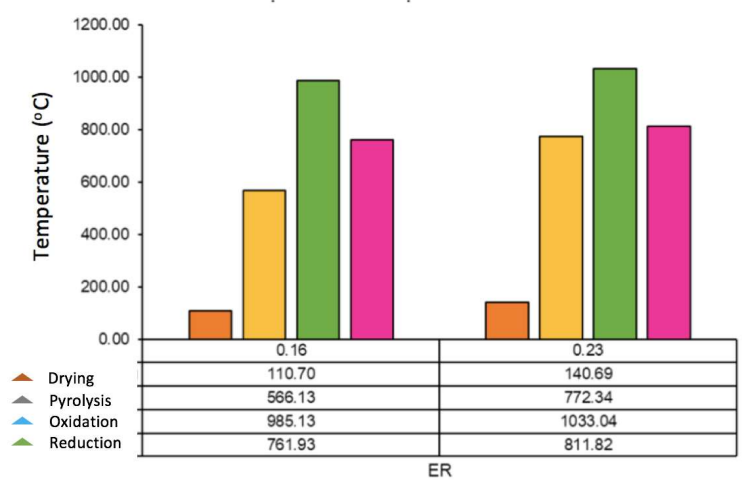

Fig. 8. Temperature of each gasification zone at ER 0.16 and 0.23

At ER 0.23 , a given secondary air supply of $0.00033 \mathrm{~m}^{3} / \mathrm{s}$. The amount of air discharge caused the operating temperature in each zone to increase from $110.70{ }^{\circ} \mathrm{C}$ to $140.69^{\circ} \mathrm{C}$ in the dryer zone, $566.13{ }^{\circ} \mathrm{C}$ to $772.34{ }^{\circ} \mathrm{C}$ in pyrolysis zone, $985.13{ }^{\circ} \mathrm{C}$ to $1033.04{ }^{\circ} \mathrm{C}$ in the oxidation zone, and $761.93{ }^{\circ} \mathrm{C}$ to $811.82{ }^{\circ} \mathrm{C}$ (see Fig. 8. above).

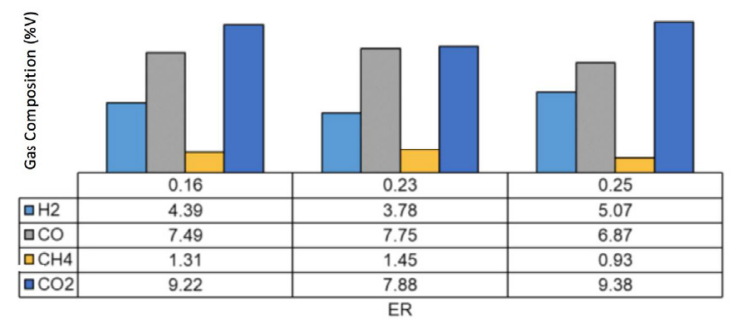

Fig. 9. Gas Composition at ER 0.16; 0.23; and 0.25.

At ER 0.23 (see Fig. 9.) an appropriate air supply causes the energy portion for tar breaking and gas formation to take place evenly. This is seen from the high temperatures in each zone and the gas composition as well as the increased operating duration of 696 seconds (ER 0.16) to 807 seconds. This high operating temperature causes the breakdown of rice husk into other compounds take place properly and the formation of gas can burn to run optimally.

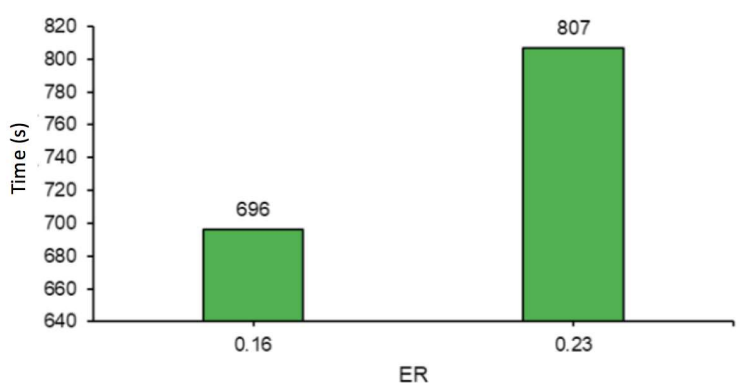

Fig. 10. Duration of ER Operations 0.16 and 0.23

From the ER temperature data of 0.23 and 0.25 previously discussed, the authors found that increasing ER values did not mean that the temperature also increased linearly. This can be caused by a loss of air supply so as not to affect the reaction of each gasification zone. Alternatively, the process is not a gasification process but a burning process.

When viewed at ER 0.25 where the amount of air is twice as large as the amount of air at ER 0.23, the reaction is not fully gasified. This can be seen from the high value of $\mathrm{CO}_{2}$ of $9.38 \%$ while the value of $\mathrm{CO}_{2}$ in ER 0.23 is only $7.88 \%$ (see Fig. 10.). This indicates the gasification reaction at ER 0.25 does not go well. Existing heat is only good for tar breakdown, but not optimal for gas-burning formation.

\section{Conclusion}

This study aims to determine the simultaneous effect of secondary air intake through variation of Equivalence Ratio (ER) to tar reduction in gas producer and gasification efficiency. The dual air supply system means providing additional air supply to the gasification reactor. From the result of the research, it is found that with the implementation of secondary air intake in $\mathrm{Z}=38 \mathrm{~cm}$ position right in pyrolysis zone, in ER 0.25 can reduce tar as much as $80,82 \%$ with tar content at gas producer equal to 11,62 gram / Nm3 . While at ER 0.23 obtained the highest gasification efficiency value of $33.41 \%$.

\section{References}

1. Basu, P. Biomass Gasification and Pyrolysis Handbook. CRC Press.(2010)

2. FAO. FAO Statistical Pocketbook 2015. Food and Agriculture Organization of the United Nations. (2015)

3. Galindo, A. L., Lora, E. S., Andrade, R. V., Giraldo, S. Y., Jaén, R. L., \&Cobas, V. M. Biomass gasification in a downdraft gasifier with a twostage air supply: Effect of operating conditions on gas quality. Biomass and Bioenergy, 61, 236244.(2014)

4. Molino, A., Chianese, S., \&Musmarra, D..Biomass gasification technology: The state of the art overview. Journal of Energy Chemistry, 25(1), 10 25. (2016)

5. Pode, R. Potential applications of rice husk ash waste from rice husk biomass power plant. Renewable and Sustainable Energy Reviews, 53, 
1468-1485. (2016)

6. Susastriawan, A. A. P., Saptoadi, H., \&Purnomo. Small-scale downdraft gasifiers for biomass gasification: A review. Renewable and Sustainable Energy Reviews, 76 (March), 989-1003. (2017)

7. Zhai, M., Wang, X., Zhang, Y., Dong, P., Qi, G., \& Huang, Y. Characteristics of rice husk tar secondary thermal cracking.Energy, 93, 13211327. (2015)

8. Dafiqurrohman, H., Surjosatyo, A., Gibran, F. R.
Air intake modification for pyrolysis optimization on rice husk fixed bed downdraft gasifier with maximum capacity of $30 \mathrm{~kg} / \mathrm{hour}$. International J. of Technology, 8, 1117-1127. (2016)

9. F.R. Gibran, A. Surjosatyo, A.A. Hermawan, H. Dafiqurrohman, M.B. Anggriawan, N.R. Yusuf, S. Maarif. Optimization of fixed bed downdraft reactor for rice husk biomass gasification using secondary air intake variation. International $\mathrm{J}$. of Technology. 2: 390-399. (2018) 